\title{
Poly(dimethyl-siloxane) (PDMS) based micro-optical beam splitters
}

\section{Divisores de haz micro ópticos basados en poli(dimetilsiloxano) (PDMS)}

\author{
Jordi Vila-Planas ${ }^{(1, *)}$, Stefanie Demming(2), Stephanus Büttgenbach ${ }^{(2)}$, Andreu Llobera(1) \\ 1. Institut de Microelectrònica de Barcelona, IMB-CNM, CSIC, Spain. \\ 2. Institut für Mikrotechnik, Technische Universität Braunschweig, Germany. \\ (") Email: jordi.vila@csic.es
}

Recibido / Received: 29/09/2011. Revisado / Revised: 06/02/2011. Aceptado / Accepted: 20/02/2012.

\begin{abstract}
:
A micro-optical beam splitter for integrated optical devices has been designed, fabricated and characterized. Two main configurations of the beam splitters are defined: $1 \times 2$ and $1 \times 4$. The fabrication is based on soft-lithography and requires a single photolithographic step for master definition. The device is replicated in poly(dimethyl-siloxane) (PDMS). Its working principle is based on total internal reflection. Optical elements e.g., lenses, mirrors and beam splitters, based on PDMS and air as constituent materials are defined. A self alignment system for optical fibers has been also fabricated. Losses of $7.8 \pm 1.2 \mathrm{~dB}$ for a single beam division are obtained.
\end{abstract}

Key words: Beam splitter, PDMS, Micro-Optics, Air Mirrors, Soft-Lithography.

\section{RESUMEN:}

Se ha diseñado, fabricado y caracterizado un divisor de haz micro-óptico con dos geometrías diferentes, $1 \times 2$ y $1 \times 4$. La fabricación se basa en el método de litografía blanda y requiere un único paso fotolitográfico para la definición del máster. El dispositivo se replica usando poli(dimetilsiloxano) (PDMS). El funcionamiento del dispositivo se basa en la implementación de lentes, espejos y divisores de haz, definidos únicamente con PDMS y aire. También se han fabricado unos sistemas de auto-alineamiento para poner las fibras. Las perdidas en cada división del haz son de $7.8 \pm 1.2 \mathrm{~dB}$.

Palabras clave: Divisor de Haz, PDMS, Micro-Óptica, Espejos de Aire, Soft-litografía.

\section{REFERENCIAS Y ENLACES / REFERENCES AND LINKS}

[1]. S. E. Miller, "Integrated optics. Introduction", Bell System Tech. J. 48, 2059-2069 (1969).

[2]. J. M. Heaton, R. M. Jenkins, D. R. Wight, J. T. Parker, J. C. H. Birbeck, K. P. Hilton, "Novel I-to-N way integrated optical beam splitters mixing in GaAs/AIGaAs multimode waveguides using symmetric mode", Appl. Phys. Lett. 61, 1754-1756 (1992).

[3]. D.J. Thomsom, Y. Hu, G. T. Reed, J.-L. Fedeli., "Low loss MMI couplers for high performance MZI modulators", IEEE Photonic. Tech. L. 22, 1485-1487 (2010).

[4]. A. Manz, N. Graber, H. M. Widmer, "Miniaturized total chemical analysis systems: A novel concept for chemical sensing", Sensor. Actuat. B 1, 244-248 (1990).

[5]. E. Yablonovitch, T. J. Gmitter, K. M. Leung, "Photonic band structure: The face-centered-cubic case employing nonspherical atoms", Phys. Rev. Lett. 67, 2295-2299 (1991).

[6]. C. J. Choi, B. T. Cunningham, "Single-step fabrication and characterization of photonic crystal biosensors with polymer microfluidic channels", Lab. Chip 6, 1373-1380 (2006).

[7]. S. T. Shamah, B. T. Cunningham, "Label-free cell-based assays using photonic crystal optical biosensors", Analyst 136, 1090- 1102 (2011). 
[8]. J. T. Heeres, P. J. Hergenrother, "High-throughput screening for modulators of protein-protein interactions: use of photonic crystal biosensors and complementary technologies", Chem. Soc. Rev. 40, 4398-4410 (2011).

[9]. R. Bernini, G. Testa, L. Zeni, P. M. Sarro, "Integrated optofluidic Mach-Zehnder interferometer based on liquid core waveguides", Appl. Phys. Lett. 93, 011106 (2008).

[10].G. Testa, Y. Huang, P.M. Sarro, L. Zeni, R. Bernini, "High-visibility optofluidic Mach-Zehnder interferometer", Opt. Lett. 35, 1584-1586 (2010).

[11].R. Bernini, E. De Nuccio, F. Brescia, A. Minardo, L. Zeni, P. M. Sarro, R. Palumbo, M. R. Scarfi, "Development and characterization of an integrated silicon micro flow cytometer", Anal. Bioanal. Chem. 386, 1267-1272 (2006).

[12]. A. Llobera, R. Wilke, S. Büttgenbach, "Enhancement of the response of poly(dimethylsiloxane) hollow prisms through air mirrors for absorbance-based sensing", Talanta 75, 473-479 (2008).

[13].Y. Xia, G. M. Whitesides, "Soft lithography", Angew. Chem. Int. Edit. 37, 550-575 (1998).

[14]. M. Weisser, G. Tovar, S. Mittler-Neher, W. Knoll, F. Brosinger, H. Freimuth, M. Lacher, W. Ehrfeld, "Specific bio-recognition reactions observed with an integrated Mach-Zehnder interferometer", Biosens. Bioelctron. 14, 405-411 (1990).

[15].B. H. Jo, L. M. Van Lerberghe, K. M. Motsegood, D. J. Beebe, "Three-dimensional micro-channel fabrication in polydimethylsiloxane (PDMS) elastomer", J. Microelectromech. S. 9, 76-81 (2000).

\section{Introduction}

Integrated optics has been an active research area since the early 1970's [1]. In order to introduce beam splitters (BSs) in integrated optics technology, many specific requirements had to be solved and many different optical properties have been used to solve this issue. Heaton and co. [2] presented one of first integrated beam splitters called Multimode Interference (MMI) splitters. This kind of beam splitters are still a research topic [3]. However, MMI beam splitters requires very precise fabrication techniques and are wavelengthdependent. This is a strong drawback for micro total analysis systems ( $\mu$ TAS) [4] [or Lab-on-achip (LoC)], mainly focused on the "white light spectroscopy" concept.

Another alternative are Y-junction beam splitters, they have simpler design requirements and could also be valid for any working wavelength. Nevertheless, the shape of Yjunction, and concretely the edge requires highresolution fabrication techniques. These structures are also difficult to align with input and output optical fibers.

More recently Bernini and co. [9-10] have reported liquid-core antiresonant reflecting optical waveguide (ARROW), confining the light in a microfluidic device. As beam splitters, they use Y-junction [9] and T-branch [10]. However, the fabrication process for ARROW waveguides requires several clean room steps [11], making the device more expensive.

Another different approach for integrated optics applications with promising results are photonic crystals (PCs) [5]. PCs have shown excellent optical properties and a myriad of applications on LoC systems [6-8], however the wavelength dependence, design and fabrication requirements are even stronger than in previous cases, hampering their application in real systems.

In order to avoid all these drawbacks a micro-optic structure is presented. Focusing on LoC applications the desired properties for our device are continuous spectrum response, low cost, reduction of fabrication requirements as well as easy-to-use connectorization system. Therefore, PDMS is a perfect candidate to work with for its high transmittance range (from visible to near infra-red), its technological simplicity and its low cost. Moreover, PDMS has shown capacity to define air mirrors relaxing the total internal reflection (TIR) condition [12] and also implement self-alignment systems.

\section{Methods and materials}

\subsection{Design}

Having in mind LoC applications, micro-optics devices such as interferometers have already 
been reported [14]. Nevertheless, the presented device is an step forward due to its high integration degree, with self-alignment structures, collimation lenses, air mirrors and beam splitters.

In the presented structure, the refractive indices (RI) used to calculate the TIR conditions are $n_{P S M S}=1.41$ and $n_{\text {air }}=1$. Using the Snell's law one can obtain the critical angle $\left(\theta_{c}\right)$ from which all the light would be reflected at PDMSair interface, $\theta_{c}=45.17^{\circ}$. Therefore, this $\theta_{c}$ allows the definition of air mirrors as shown in Fig. 1.

In this kind of structures the collimation of the beam is very important in order to achieve a good intensity rate distribution. In this frame, PDMS and air can also be used for implementing optical cylindrical-lenses, thus enhancing the system performance.

The ray tracing simulations have been performed using OSLO $\mathrm{Edu}^{\odot}$ software and the results are shown in Fig. 2. The simulations are made considering a numerical aperture of 0.22 .

Three interfaces between air and PDMS were designed. The first one has a curvature of 250 $\mu \mathrm{m}$. Second and third lenses have a curvature radius of $350 \mu \mathrm{m}$.

Once the beam collimation is ensured, the design of the structure for $1 \times 2$ and $1 \times 4$ beam splitters has to be optimized. First of all optical fibers with a cladding width of $230 \mu \mathrm{m}$ has been chosen to maximize the beam width. Also a clamp system to fix optical fibers on the desired position has been developed.

The beam splitters consist of a sharp pyramid with tilted walls at $45^{\circ}$ to fulfill the TIR condition. Then the light is turned $90^{\circ}$ with another air mirror to reach the output. A schematic view of both configurations, $1 \times 2$ and $1 \times 4$, can be seen on Fig. 3 .

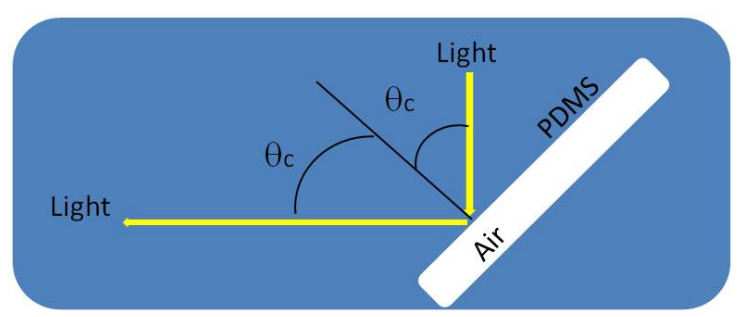

Fig. 1: Schematic working principle of air mirrors.

\subsection{Fabrication}

The fabrication technique is based on softlithographic methods [13], as detailed below:

Master: Firstly a $700 \mu \mathrm{m}$-thick soda-lime glass wafer is dehydrated for $1 \mathrm{~h}$ at $200^{\circ} \mathrm{C}$. After that, a thin layer of $\mathrm{Cr}$ is sputtered to improve the master adherence. Afterwards, the substrate is dehydrated for $1 \mathrm{~h}$ at $150^{\circ} \mathrm{C}$, and then a seed layer of SU-8 (MicroChem, Corp., Newton, MA, USA) is spun ( $\sim 4 \mu$ thick $)$ over the wafer in order to increase the adherence of the master. Then, a soft-bake $\left(15 \mathrm{~min}\right.$ at $\left.95^{\circ} \mathrm{C}\right)$ followed by a floodexposure $\left(\lambda=365 \mathrm{~nm}\right.$ and $\left.55 \mathrm{~mJ} / \mathrm{cm}^{2}\right)$ is performed.

Once the seed layer is finished, a SU-8 50 layer is spinned achieving a thickness of $250 \mu \mathrm{m}$. This thickness has been chosen to facilitate the insertion of the fibers. After that, a soft-bake at $950 \mathrm{C}$ during $3 \mathrm{~h}$ has been made followed by an exposure of $750 \mathrm{~mJ} / \mathrm{cm}^{2}$. Finally the master is developed using propylene glycol methyl ether acetate (PGMEA, MicroChem, Corp., Newton, MA, USA).

Replica: The pre-polymer is obtained by mixing the curing agent and the elastomer in a 1:10 (v:v) ratio. Then, the pre-polymer is degassed removing possible bubbles and the master is filled. Afterwards, PDMS is cured for $20 \mathrm{~min}$ at $80^{\circ} \mathrm{C}$.

Bonding: Finally the replica is peeled off and bonded to a glass substrate by an oxygen plasma (12s at $500 \mathrm{~W}$ ) [15].

\section{Results and discussion}

All the measurements have been done using a $635 \mathrm{~nm}$ laser (S1FC 635, THORLABS) with a nominal power of $100 \mu \mathrm{W}$.



Fig. 2: Ray tracing simulations run in OSLO Edu ${ }^{\odot}$, where dimensions are in $\mathrm{mm}$. 


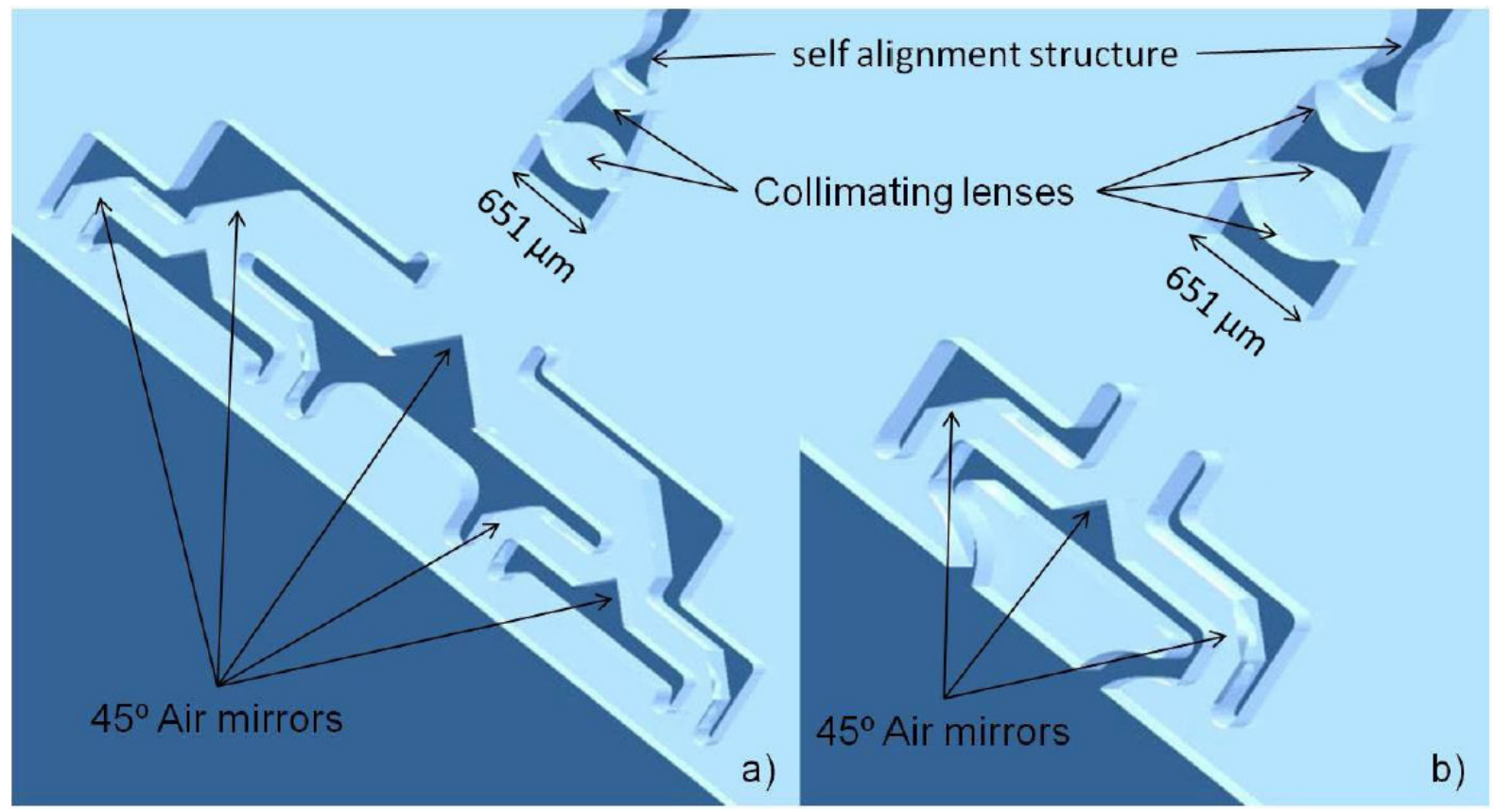

Fig. 3: Detailed view of both configurations, a) $1 \times 4$ and b) $1 \times 2$ beam splitters.

Power results are plotted in Table I. The total power calculation for each beam splitter configuration is the sum of all the output channels. From these results losses associated to a single beam division are $7.8 \pm 1.2 \mathrm{~dB}$. However, these losses do not properly differentiate between propagation or beam division. This point would require further study to know exactly how many losses are associated to propagation or to beam division itself.

As can be seen in Table I, there is an increase of relative losses when the number of beam divisions increase. This phenomenon may be due to a suboptimal alignment of fibers optics, producing power asymmetry between the optical path of the BSs.

Finally an analysis of intensity profile has been done. Figures 4(a) and 4(b) show the expected results considering the shape of the channel, the square shape at the output. Just the expected result due to shape of the waveguide. However, some unexpected results appear between the guided light. These smalls slits are the edge of the BSs, where the light do not fulfill the TIR condition.
Table I

Power results for $1 \times 2$ and $1 \times 4$ beam splitters.

\begin{tabular}{c|c|c} 
BS & Total power & Single channel power \\
\hline \hline $1 \times 2$ BS & $9.1 \mu \mathrm{W}$ & $4.4 \pm 1.2 \mu \mathrm{W}$ \\
\hline $1 \times 4$ BS & $2.9 \mu \mathrm{W}$ & $0.7 \pm 0.3 \mu \mathrm{W}$
\end{tabular}


Fig. 4: Intensity profile. (a) Complete picture of intensity profile at $1 \times 4$ BS output (b) $3 \mathrm{D}$ reconstruction of intensity profile of single channel in the $1 \times 2$ BS output. Dimensions of $\mathrm{X}$ and $\mathrm{Y}$ axis are pixels while $\mathrm{Z}$ axis dimension is an intensity scale normalized to 1 . 


\section{Conclusions}

A polymeric micro-optical device has been designed, fabricated and characterized. Several sub-elements has been designed, fabricated and characterized such as cylindrical lenses, clamping systems and BSs itself. The presented BSs are low cost, do not depend on wavelength from visible to near infrared and may be a useful for more complex devices such as integrated interferometers.

The presented results show good performance with a good balancing between optical channels. However, further study to know exactly which are the losses produced on the beam division as well as on the propagation inside the optical channels is required.

\section{Acknowledgements}

The research leading to these results has received funding from the European Research Council under the European Community Seventh Framework Programme (Grant FP7/20072013)/ ERC Grant Agreement No. 209243. 